\title{
Matéria
}

Revista Matéria, v. 11, n. 1, pp. 41 - 47, 2006

ISSN 1517-7076

http://www.materia.coppe.ufrj.br/sarra/artigos/artigo10691

\section{Influence of Temperature on the Properties and Phase Transformations in Ti-Nb Alloys with $2 \% \mathrm{Al}$}

\author{
Lioudmila A. Matlakhova $^{\mathrm{a}}$, Anatoly N. Matlakhov ${ }^{\mathrm{a}}$ Sergio N. Monteiro ${ }^{\mathrm{a}}$, Sergei G. Fedotov ${ }^{\mathrm{b}}$ \\ a State University of the Northern Rio de Janeiro, UENF, Advanced Materials Laboratory, LAMAV, Av. \\ Alberto Lamego, 2000, 28013-602, Campos dos Goytacazes, Brazil,* \\ e-mail: lioudmila@uenf.br, anatoly@uenf.br, sergio.neves@ig.com.br \\ ${ }^{\mathrm{b}}$ Laboratory for Amorphous and Nanocrystalline Alloys, A.A. Baikov Institute of Metallurgy and Materials \\ Science, Russian Academy of Science, Moscow, Russia.
}

\begin{abstract}
Quenched alloys from the Ti-Nb system are of considerable scientific and applied interest due to properties such as superconductivity, shape memory effect and high damping capacity. In this work, Ti-Nb quenched alloys with $2 \mathrm{wt}$.\% Al and $\mathrm{Nb}$ content varying from 15 to $40 \%$ were investigated with respect to effects on phase transformations, internal friction and elastic modulus caused by the temperature up to $800^{\circ} \mathrm{C}$. The results showed that the internal friction presented peaks and the elastic modulus displayed minimum values with the temperature. These results were associated with phase transformations occurring with increasing temperature.
\end{abstract}

Keywords: Ti-Nb-2\%Al, temperature effects, phase transformations, elastic modulus, internal friction.

\section{INTRODUCTION}

Titanium-Niobium alloys have been applied in technological systems related to special phenomena of electrical superconductivity, shape memory effect and superelasticity [1, 2$]$. Moreover, the elastic properties and related increase in the internal friction of the Ti-Nb crystalline lattice result in a high damping capacity. The addition of other elements to the composition of Ti-Nb alloys can significantly change the value of the elastic effects and, in some cases, enhance the alloys properties. In particular, the introduction of aluminum tends to increase both, the elastic modulus and the internal friction.

Previous works on Ti-Nb-Al alloys have shown that, even in relatively small amounts, aluminum can cause relevant changes in the microstructure and physical behavior. For instance, Matlakhova et allii [י5] investigated the effects of 2 to $15 \mathrm{wt} . \%$ addition of $\mathrm{Al}$ on the microstructure and physical properties of Ti alloys with 10 to $40 \mathrm{wt} \% \mathrm{Nb}$. The microstructure was studied in terms of phase transformations and related changes in properties such as the Young's modulus (E), the shear modulus (G), the density $(\rho)$ and the internal friction $\left(\mathrm{Q}^{-1}\right)$. The authors $[\underline{3}-\underline{5}]$ found that the introduction of $\mathrm{Al}$ promotes a rhombic distortion in the original $\alpha$ ' hexagonal close-packed (HCP) martensitic structure of the Ti-Nb alloy. This martensitic structure then transforms to an $\alpha$ " orthorhombic structure. For alloys with the inferior limit of 2 wt.\% Al, the rhombic distortion will take place at $\mathrm{Nb}$ content as low as 15 wt.\%. As a consequence a duplex $\alpha^{\prime}+\alpha^{\prime \prime}$ microstructure will exist from 15 to $24 \mathrm{wt}$ \% Nb. Above this, from 24 to $30 \mathrm{wt} . \% \mathrm{Nb}$, the $\alpha$ " structure is partially transformed into a metastable $\omega$ phase that gradually changes to a metastable $\beta$ body centered cubic (BCC) phase. At even higher Nb percentages, from 30 to $35 \mathrm{wt} \%$, a triplex $\alpha^{\prime}+\alpha$ ” $\beta$ microstructure will exist $[\underline{5}, \underline{6}]$. Finally, from 35 to 40 wt. $\%, \alpha$ ' disappears leaving a duplex $\alpha ”+\beta$ microstructure. From 40 wt.\% $\mathrm{Nb}$ and above, a single stable BCC $\beta$ phase microstructure predominates.

All these complex microstructural changes brought by the addition of only 2 wt.\% Al strongly affect the physical properties of Ti-Nb alloys. For example, the appearance of the $\omega$ or the $\beta$ metastable phases for Ti-Nb-2 wt.\% Al alloys is directly responsible for increases in E, G, $\rho$ and $\mathrm{Q}^{-1}[\underline{6}, \underline{7}]$.

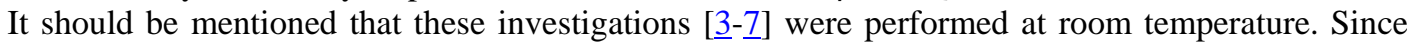
temperature is known to markedly alter the microstructure and the physical properties of alloys, the present 
work have studied changes caused by temperature, up to $800^{\circ} \mathrm{C}$, on the phase transformation and values of $\mathrm{E}$, $\mathrm{G}, \rho$ and $\mathrm{Q}^{-1}$ in Ti-Nb alloys with 2 wt.\% Al.

\section{EXPERIMENTAL PROCEDURE}

\subsection{Materials}

The 2 wt.\% Al and 15 to $40 \mathrm{wt} . \% \mathrm{Nb}$ with balanced Ti alloys investigated in the present work were electric arc furnace fabricated through five consecutive melts using high purity elements. The titanium was iodized and 99.99 wt.\% pure. The niobium was electron beam zone refined and 99.9 wt.\% pure. The aluminum was electrolytically refined and $99.999 \mathrm{wt} . \%$ pure.

After solidification, ingots weighting $100 \mathrm{~g}$ were encapsulated under vacuum and heat-treated at $1200^{\circ} \mathrm{C}$ for 5 hours to homogenize the microstructure. In the following step, the homogeneous alloy ingots were re-heated at $1200^{\circ} \mathrm{C}$ in Argon atmosphere and forged as cylindrical bars with $8 \mathrm{~mm}$ in diameter. These forged bars were then machined down to $6 \mathrm{~mm}$ in diameter to discard any surface contamination.

Two types of samples were transversally cut from the machined bars. Samples with $80 \mathrm{~mm}$ in length were cut for the determination of $\mathrm{E}, \mathrm{G}$ and $\mathrm{Q}^{-1}$. Samples with $20 \mathrm{~mm}$ in length were cut for differential thermal analysis (DSC) and microstructure characterization.

All these samples were again vacuum encapsulated, in the same previous procedure as for the ingots, and then heat-treated at $1000^{\circ} \mathrm{C}$ for 5 hours. This was immediately followed by water quenching. Consequently, the initially investigated alloy microstructure was a quenched martensite and not that predicted by the phase diagram at room temperature.

\subsection{Properties and Microstructure Evaluation}

As for the physical properties the elastic moduli, E and G, were obtained by dynamic resonance through the equations:

$$
\begin{aligned}
& E=4.0775 \rho \mathrm{l}^{2} \mathrm{f}_{\mathrm{l}}^{2} \\
& \mathrm{G}=4.0775 \rho \mathrm{l}^{2} \mathrm{f}_{\mathrm{t}}^{2}
\end{aligned}
$$

Where $f_{l}$ and $f_{t}$ are, respectively, the longitudinal and the transversal oscillations corresponding to the resonance frequencies. The length $l$ and the density $\rho$ of the alloy sample were also measured by standard procedure. The resonance frequencies were determined in an Elastomat equipment in which the oscillation could vary up to $26 \mathrm{kHz}$ at a maximum stress of $0.1 \mathrm{MPa}$ and a temperature in the range of 20 to $750^{\circ} \mathrm{C}$ with a heating rate of $2^{\circ} \mathrm{C} / \mathrm{min}$.

The evaluation of the damping capacity of the alloys crystalline lattice was carried out by measurements of the internal friction $\mathrm{Q}^{-1}$. These measurements were performed in the same Elastomat equipment coupled with an oscillatory excitation device with possibility of changing the temperature up to $800^{\circ} \mathrm{C}$.

The DSC curve for the thermoanalysis was obtained in a Seteram, model DSC-3, equipment from 20 to $800^{\circ} \mathrm{C}$ with heating and cooling rates of $2^{\circ} \mathrm{C} / \mathrm{min}$.

The microstructure of the quenched alloys was analyzed on discs collected from the samples using a Miniton cutter. The discs were cold mounted in rigid polymeric resin before surface preparation. This preparation was initially done by grinding with a sequence of conventional emery papers followed by polishing down to $0.25 \mu \mathrm{m}$ diamond paste. The polished surface was finally electrolytically etched at $30 \mathrm{~V}$ in a $12 \mathrm{ml} \mathrm{HNO}_{3}+2 \mathrm{ml} \mathrm{HF}+100 \mathrm{ml} \mathrm{H}_{2} \mathrm{O}$ solution. The microstructure was then observed in a model 32 Neophot optical microscope.

\section{RESULTS AND DISCUSSION}

Figure 1 shows the microstructure of three quenched Ti-Nb-2wt.\% Al with different niobium contents: (a) $15 \mathrm{wt} \% \mathrm{Nb}$, (b) $30 \mathrm{wt} . \% \mathrm{Nb}$ and (c) $40 \mathrm{wt} . \% \mathrm{Nb}$. Regarding three microstructures shown in Figure 1, it is important to mention that the observed grain boundaries correspond to the stable BCC $\beta$ phase formed at $1000^{\circ} \mathrm{C}$ just before quenching. 

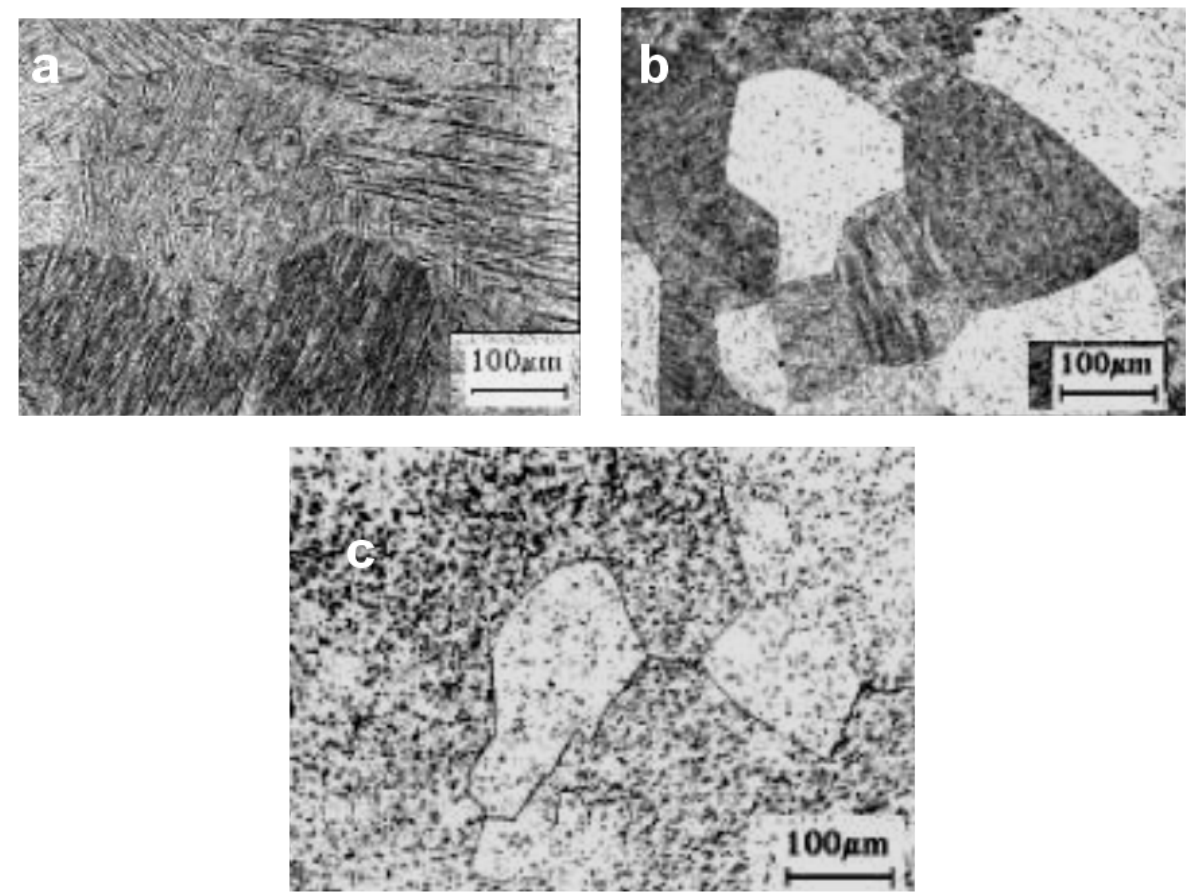

Figure 1: Micrographs of the alloys with: (a) 15, (b) 34 and (c) 40 wt.\%Nb.

Alloys with relatively low amount of Nb, such as 15 wt.\% in Figure 1(a), develop, after quenching, a microstructure completely covered by $\alpha$ martensite plates. For 34 wt.\% Nb, Figure 1(b), a complex microstructure is observed in which metastable $\beta$ phase has partially replaced $\alpha$ ' and $\alpha$ ” phases [즌 $\underline{5}$ ]. For 40 wt.\% Nb, Figure 1(c), no martensite plate is formed after quenching and the microstructure consists of the same $\beta$ phase formed at $1000^{\circ} \mathrm{C}$ [ㅁ-ㄱ] .
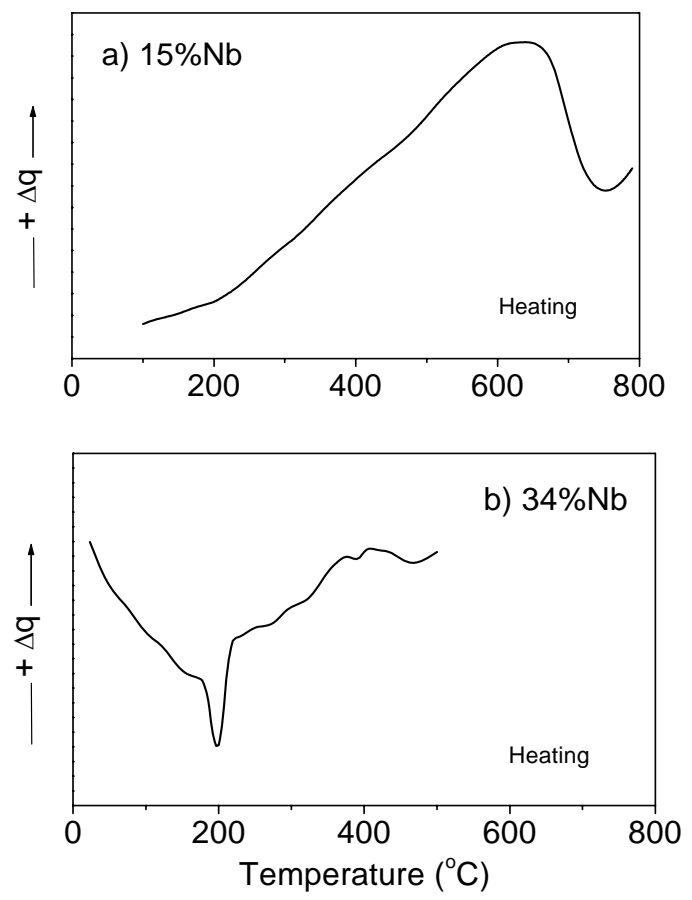

Figure 2: DSC curves for the quenched alloys: (a) Ti-15wt.\%Nb-2wt.\%Al and (b) Ti-34wt.\%Nb-2wt.\%Al.

Figure 2 illustrates the DSC behavior for two quenched Ti-Nb-2 wt.\% Al alloys with $15 \mathrm{wt} \% \mathrm{Nb}$ (a) and 34 wt.\% Nb (b). One should notice for the alloy with 15 wt.\% Nb, Figure 2(a), a steady increase in 
the curve until $600^{\circ} \mathrm{C}$. This increase can be attributed to the thermal energy liberated by intermediate transformations of the martensitic HCP $\alpha$ ' phase into stable HCP $\alpha$ phase. Above $650^{\circ} \mathrm{C}$ there is an endothermic peak in Figure 2(a) with a minimum around $750^{\circ} \mathrm{C}$.

This peak can be associated with the final transformation of stable $\alpha$ phase into stable BCC $\beta$ phase [5-7]. On the other hand, the alloy with $34 \mathrm{wt} . \% \mathrm{Nb}$ in Figure 2(b) displays two distinct thermal effects. An endothermic peak occurs with a minimum around $190^{\circ} \mathrm{C}$. This peak can be related to the orthorhombic $\alpha$ " phase transformation into metastable BCC $\beta$ phase. An exothermic valley can be observed in the interval from 330 to $460{ }^{\circ} \mathrm{C}$. Actually, this valley corresponds to the superposition of different processes, including the decomposition of the $\beta$ metastable phase forming other phases that are richer and poorer in alloying elements. The poor alloying phase will consolidate in the stable non-martensitic $\alpha$ phase, which then may transform into stable $\beta$ phase at higher temperatures [7]. The alloying rich regions will directly form the stable $\beta$ phase since $\mathrm{Nb}$ is a BCC stabilizer.

Figure 3 illustrates the variation of the internal friction $\mathrm{Q}^{-1}$ with temperature for two alloys, one with $15 \mathrm{wt} . \% \mathrm{Nb}$ (a) and the other with $34 \mathrm{wt} . \% \mathrm{Nb}$ (b). The variation of $\mathrm{Q}^{-1}$ with temperature shown in Figure 3 can be associated with the phase transformations mentioned in the introduction of this work and illustrated in Figure 1.

For the alloy with $15 \mathrm{wt} . \% \mathrm{Nb}$, Fig 3(a), the values of $\mathrm{Q}^{-1}$ are about $5 \times 10^{-4}$ to $20 \times 10^{-4}$ up to $450^{\circ} \mathrm{C}$ in association with an $\alpha^{\prime}$ or $\alpha^{\prime \prime}-\alpha\left(\alpha^{\prime \prime}\right)$ - microstructure. When the transformation of stable $\alpha$ phase into stable $\beta$ phase takes place above $600^{\circ} \mathrm{C}$, the values of $\mathrm{Q}^{-1}$ significantly increase up to $50 \times 10^{-4}$. Whereas, the alloy with $34 \mathrm{wt} . \% \mathrm{Nb}$, Figure 3(b), displays, up to $450^{\circ} \mathrm{C}$, maximum values in $\mathrm{Q}^{-1}$ of almost $50 \times 10^{-4}$ during the already discussed phase transformation of $\alpha$ " into metastable $\beta$ followed by decomposition of metastable $\beta$ into stable $\alpha$ phase. As in the alloy with $15 \mathrm{wt} . \% \mathrm{Nb}$, the alloy with $34 \mathrm{wt} \% \mathrm{Nb}$, Figure 3(b), increases the value of $\mathrm{Q}^{-1}$ as the temperature rises above $600^{\circ} \mathrm{C}$ due to the transformation of stable $\alpha$ into stable $\beta$ phase. Similar behavior was found for the other alloys investigated.
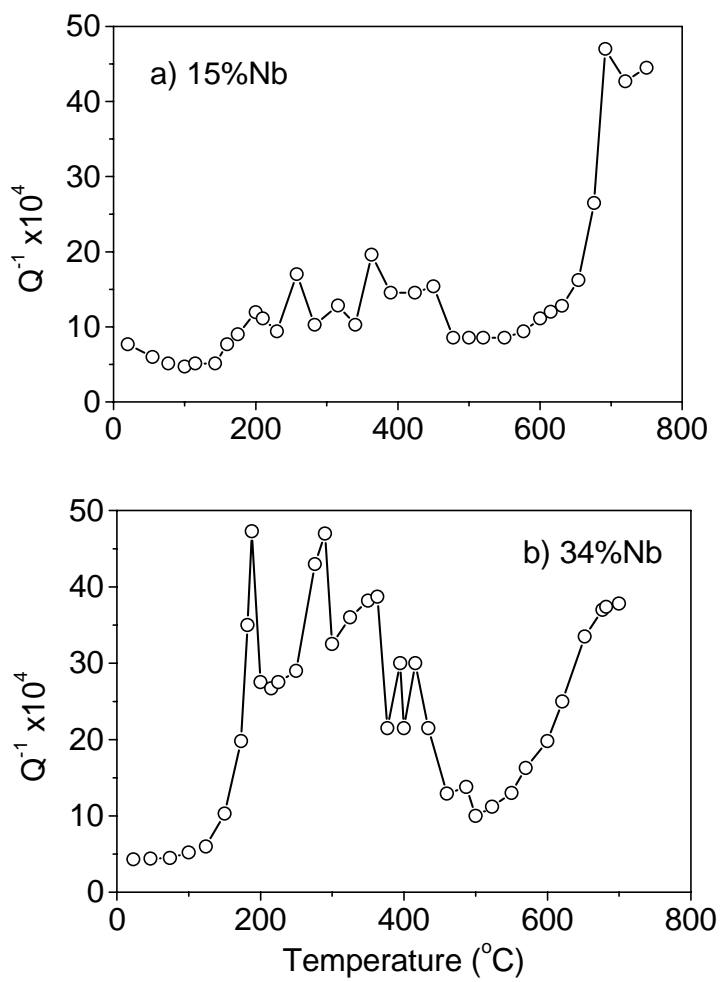

Figure 3: Variation of the internal friction, $\mathrm{Q}^{-1}$, with temperature for the quenched alloys: (a) Ti-15wt.\%Nb2wt.\%Al and (b) Ti-34wt.\%Nb-2wt.\%Al.

Figure 4 illustrates the variation of the elastic moduli, E and G, with temperature for the Ti-34 wt.\% $\mathrm{Nb}-2$ wt.\% Al alloy. In this figure a minimum in the value of both $\mathrm{E}$ and $\mathrm{G}$ occurs around $200^{\circ} \mathrm{C}$. Minimum values were also obtained for alloys with different $\mathrm{Nb}$ content. However, for each alloy the temperature where the minimum occurred depends on the amount of niobium. This dependence can be seen in Figure 5 in which the E versus temperature curves for all alloys investigated is presented, including that in Figure 4. A 
similar dependence also exists for the shear modulus G. Since G follows, proportionally, the same behavior of E, Figure 4, it was not considered relevant to present a $G$ versus temperature curve for all alloys investigated.

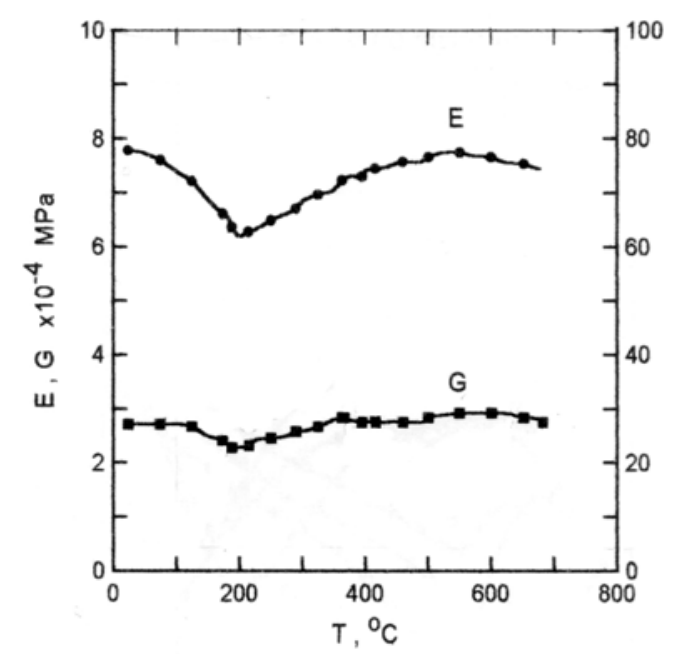

Figure 4: Variation of the moduli $\mathrm{E}$ and $\mathrm{G}$ with the temperature for the Ti-34wt.\%Nb-2wt.\%Al alloy.

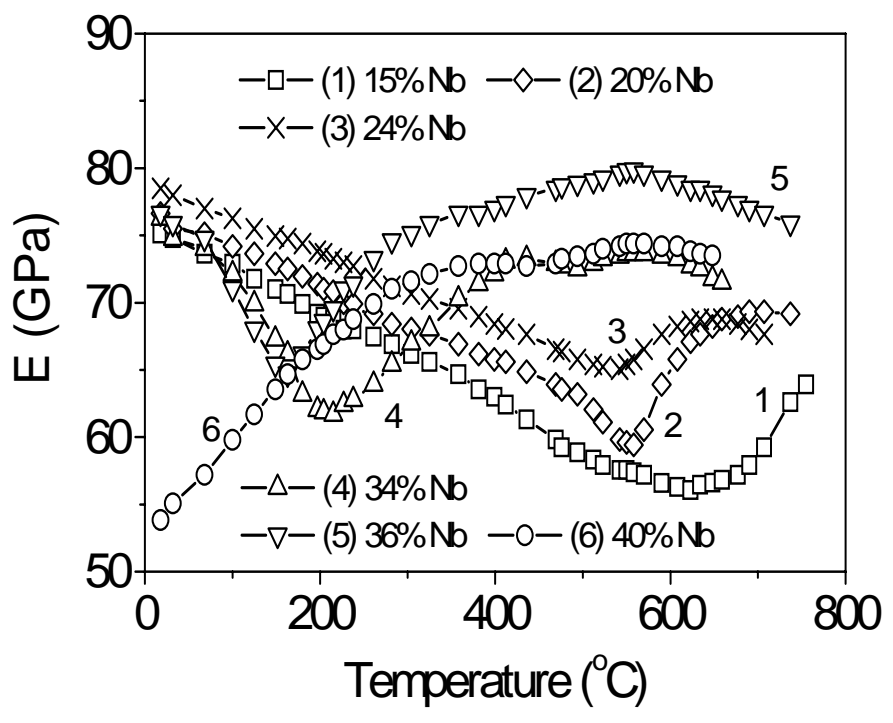

Figure 5: Temperature dependence of the elastic modulus, E, for the quenched alloys: (1) Ti-15wt.\%Nb2wt.\%Al, (2) Ti-20wt.\%Nb-2wt.\%Al, (3) Ti-24wt.\%Nb-2wt.\%Al, (4) Ti-34wt.\%Nb-2wt.\%Al, (5) Ti36wt.\%Nb-2wt.\%Al and (6) Ti-40wt.\%Nb-2wt.\%Al.

As above-mentioned, it is important to notice in Figure 4 that $\mathrm{E}$ goes through a minimum value, $\mathrm{E}_{\min }$, at different temperatures for each alloy. This minimum occurs at a comparatively higher temperature the smaller the $\mathrm{Nb}$ content. For instance, the modulus for alloy Ti- $15 \mathrm{wt} . \% \mathrm{Nb}-2 \mathrm{wt} . \% \mathrm{Al}$ at $20^{\circ} \mathrm{C}$ decreases to a minimum around $650^{\circ} \mathrm{C}$ and increases above this temperature. The Ti-40wt.\%Nb-2wt.\%Al alloy is expected to have a minimum in its modulus a little lower than $0^{\circ} \mathrm{C}$. As shall be discussed, the reason for this $\mathrm{E}_{\min }$ could be associated with phase transformations occurring with increasing temperature.

Figure 6 plots the temperature where $\mathrm{E}_{\min }$ occurs as a function of the $\mathrm{Nb}$ content. This plot conforms well to two linear branches. The different slopes of the branches indicate two distinct causes for the minimum values of E. The first branch corresponds to alloys with lower percentages of Nb, up to $24 \mathrm{wt} . \%$, and initial $\alpha^{\prime}\left(\alpha^{\prime \prime}\right)$ martensitic microstructure. These alloys are associated with minimum values of $\mathrm{E}$ and $G$ at high temperatures, above $500^{\circ} \mathrm{C}$. Their corresponding values of the modulus steadily decrease with temperature, 
Figure 5, without notable interference from any transformation down to $\mathrm{E}_{\min }$, when the lattice stiffness of the $\alpha^{\prime}$ phase is decreasing. However, when the $\alpha$ phase transforms to $\beta$ phase the situation is reversed. Since the $\beta$ phase tends to increase the stiffness of its lattice, with temperature $[\underline{1}, \underline{8}]$, the value of $\mathrm{E}$ then begins to increase. In other words, this $E_{\min }$ is a consequence of a lattice softening being overcome by the hardening contribution of the $\alpha^{\prime}\left(\alpha^{\prime \prime}\right)$ to $\beta$ transformation. At high temperatures, due to diffusion processes, the metastable phases decompose forming stable ones. Under these conditions, the reverse martensitic $\alpha^{\prime}\left(\alpha^{\prime \prime}\right)$ transformation into metastable $\beta$ and the occurrence of inelastic effects such as shape memory and superelasticity are not possible to take place.

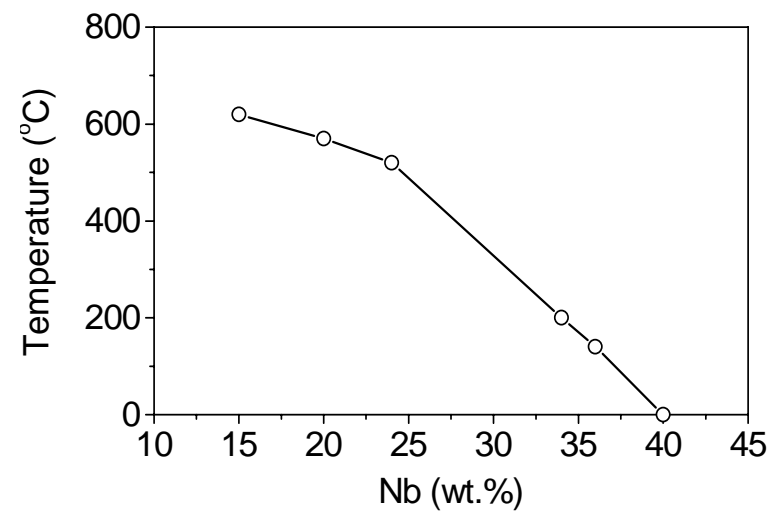

Figure 6: Dependence of the temperature of the minimum value in the modulus, $E_{\min }$, as shown in Figure 5, with the relative amount of $\mathrm{Nb}$.

The second linear branch in Figure 6, corresponding to alloys with initial duplex, $\alpha$ " $+\beta$, or single metastable $\beta$ microstructure, is associated with $\mathrm{E}_{\min }$ at low temperatures, not greater than $200^{\circ} \mathrm{C}$. In this case, an early transformation of the initial metastable $\beta$ is responsible for this behavior. At temperatures lower than $200^{\circ} \mathrm{C}, \alpha$ ' or $\alpha$ ” phase begin transforming into metastable $\beta$ as a martensitic reversible transformations. This corresponds to the endothermic peak at $190^{\circ} \mathrm{C}$, Figure 2(b), for the alloy with $34 \mathrm{wt} \% \mathrm{Nb}$. The initial metastable $\beta$ decomposes forming regions rich and poor in $\mathrm{Nb}[\underline{6}, \underline{7}]$. The rich regions become stable $\beta$ since $\mathrm{Nb}$ is a strong BCC stabilizer. The poor regions turn into the more thermodynamically stable $\alpha$, which eventually transforms into stable $\beta$. Consequently, stable $\beta$ may be formed at lower temperature, increasing the stiffness and raising the value of $E$. This explains the lower temperature $E_{\text {min }}$ displayed by alloys with 34 , 36 and 40 wt.\% Nb in Figure 5. Due to these phase transformations, alloys with Nb content between 30 to 36 wt.\% may present shape memory effect after a special heat treatment $[\underline{1}, \underline{8}, \underline{9}]$.

\section{CONCLUSIONS}

- Depending on the relative amount of $\mathrm{Nb}$, the quenching process of Ti-Nb-2 wt.\% Al alloys, from temperatures corresponding to the stable $\beta$ phase, will produce distinct structures. After heating, the initial metastable structure [ $\alpha^{\prime}$ (up to 15 wt. \% Nb), $\alpha^{\prime}+\alpha^{\prime \prime}$ (15 to $24 \mathrm{wt} \% \% \mathrm{Nb}$ ), $\alpha^{\prime}$ ( $\left.\alpha^{\prime \prime}\right)+\omega$ (24 to 30 wt.\% Nb), $\alpha^{\prime}(\alpha ”)+\beta$ (30 to 35 wt. \% Nb), $\alpha ”+\beta$ (35 to 40 wt. \% Nb) or $\beta$ (> 40 wt. \% Nb)] undergoes transformations towards a stable condition. These transformations are accompanied by endothermic and exothermic effects as well as alterations in the values of the internal friction and elastic modulus

- The internal friction presents peaks that could be associated with these phase transformations. In the case of alloys with initial metastable $\beta$ (> $30 \mathrm{wt}$. \% $\mathrm{Nb}$ ) peaks at lower temperatures were registered due to the decomposition of this phase. Above $600^{\circ} \mathrm{C}$, all alloys present an increase in internal friction as a consequence of the stable $\alpha$ to stable $\beta$ phase transformation.

- The moduli, E and G, goes through a minimum at a critical value in temperature that could be attributed to lattice softening before $\alpha^{\prime}\left(\alpha^{\prime \prime}\right)$ to $\beta$ transformation. Above this critical point, the $\beta$ phase becomes more stable and stiffer the higher the temperature. In the case of alloys with no initial $\beta$ phase, but only $\alpha$ ' $\left(\alpha\right.$ ”) martensite, up to $30 \mathrm{wt}$. \% $\mathrm{Nb}$, stable $\beta$ transforms above $500{ }^{\circ} \mathrm{C}$. Consequently, the minimum in $\mathrm{E}$ and $\mathrm{G}$ occurs at these relatively high temperatures. By contrast, 
alloys with initial $\alpha^{\prime}\left(\alpha^{\prime \prime}\right)+\beta$ or single metastable $\beta$, will suffer reverse martensitic transformation and/or $\beta$ decomposition at significantly lower temperature. Therefore, the minimum in $\mathrm{E}$ and $\mathrm{G}$ occurs at temperatures not greater than $200^{\circ} \mathrm{C}$.

\section{ACKNOWLEDGEMENTS}

The authors would like to express their thanks to the financial support provided by the Russian Academy of Science and the Brazilian agencies FAPERJ, CNPq and CAPES. Special thanks are due to Dr. V.V. Molokanov (IMET, Moscow) for the DSC tests.

\section{REFERENCES}

[1] COLLINGS, E.W., The Physical Metallurgy of Titanium Alloys, 3 ed., Metals Park, Ohio; American Society for Metals, ASM, 1984.

[2] MATTHEW, J., DONACHIE Jr., M.J., Titanium, Technical Guide, 2 ed., Materials Park, Ohio, ASM International, 2000.

[3] MATLAKHOVA, L.A., FEDOTOV, S.G., PEKHTEREVA, N.N, "Properties and Structural Characteristics of Ti-Nb-Al Alloy “, Journal News of the USSR Academy of Science, Metals. v. 3, pp. 108-113, 1994.

[4] MATLAKHOVA, L.A., FEDOTOV, S.G., MATLAKHOV, A.N., MONTEIRO, S.N., "Propriedades Físico-Mecanicas e Estruturais de Ligas Titânio-Nióbio-Alumínio“ In: Proceedings of the $51^{\text {th }}$ Annual Congress of the Brazilian Society of Metallurgy and Materials, ABM, pp. 389-402, Porto Alegre, Brazil, Aug. 1996.

[5] MATLAKHOVA, L.A., MATLAKHOV, A.N., MONTEIRO, S.N. et al., "Properties and Structure Characteristics of Ti-Nb-Al Alloys", Journal Materials Science and Engineering A, v. 393, pp. 320326, 2005.

[6] FEDOTOV, S.G., KONSTANTINOV, K.M., KOKNAEV, R.G. et al., In Yu.K. Kovneristyi (ed.), Titanium Alloys with Special Properties, Moscow, Nauka Pub., pp. 29-32, 1982.

[7] FEDOTOV, S.G., KONSTANTINOV, K.M., SINODOVA, E.P., In Yu.K. Kovneristyi (ed.), Titanium Alloys with Special Properties, Moscow, Nauka Pub., pp. 78-82, 1982.

[8] FEDOTOV, S.G. In: I.I. Kornilov (ed.), Investigations of Liquid and Solid Metals, Moscow, Nauka Pub., pp. 207-240, 1982.

[9] BAKER, C., “Shape Memory Effect on Ti-Nb-Al Alloys”, Metal Science,. v. 5, pp. 92-100, 1971. 